\title{
Double blind, placebo controlled study of nedocromil sodium in asthma
}

L Armenio, G Baldini, M Bardare, A Boner, R Burgio, G Cavagni, M La Rosa, F Marcucci, M Miraglia del Giudice, M R Pulejo, R Ronchetti, M Verini, A Vierucci, M P Villa Giovanni Cavagni Paediatric Clinic, University of Catania Mario La Rosa

Paediatric Clinic, University of Perugia Francesco Marcucci

Paediatric Clinic, University of Naples Maurizio Miraglia del Giudice

Paediatric Hospital, Casa del Sole, Palermo

Maria Rosaria Pulejo

Paediatric Clinic, University of Rome Roberto Ronchetti

Paediatric Clinic, University of Chieti Marcello Verini

Institute of Paediatrics, Hospital Meyer, Florence

Alberto Vierucci

Paediatric Clinic, University of Bologna Maria Pia Villa

Correspondence to: Professor L Armenio, Clinica Pediatrica Università di Bari, Bari, Italy.

Accepted 2 September 1992

\begin{abstract}
Paediatric Clinic, University of Bari Lucio Armenio

Paediatric Clinic, University of Pisa Giuliano Baldini

Paediatric Clinic, University of Milan Maria Bardare

Paediatric Clinic, University of Verona Attilio Boner

Paediatric Clinic, University of Pavia Roberto Burgio

Paediatric Clinic, University of Parma

Abstract

After a two week baseline, 209 asthmatic children (mean age 10 years, range 6-17) were randomly allocated to receive $4 \mathrm{mg}$ nedocromil sodium $(n=110)$ or placebo $(n=99)$ four times daily for 12 weeks in addition to their current treatment. The children completed daily diary cards and visited the clinic at four week intervals. Statistically significant differences in favour of nedocromil sodium were seen for clinician assessment of asthma severity and diary card symptom scores, pulmonary function and inhaled $\beta_{2}$ bronchodilator use. Total symptom score decreased by $50 \%$ from baseline in the nedocromil sodium group and by $9 \%$ in the placebo group during the final four weeks. Nedocromil sodium was considered very or moderately effective by $78 \%$ of children/ parents (placebo 59\%) and $73 \%$ of clinicians (placebo $50 \%$ ). Nausea, headache and sleepiness, and dyspnoea led to withdrawal of one child from nedocromil sodium and placebo treatments, respectively. Reports of sore throat and headache were marginally greater with the nedocromil sodium treatment. It is concluded that nedocromil sodium was both effective and safe in the treatment of asthma in children.
\end{abstract}

\section{(Arch Dis Child 1993;68:193-7)}

The effective management of bronchial asthma should allow a child to enjoy as near normal a lifestyle as possible and, as physicians, we have at our disposal a wide variety of treatments to help achieve this objective. ${ }^{1}$ The antiallergic agent sodium cromoglycate, for example, has been in use for many years either as a first line treatment or in conjunction with inhaled $\beta_{2}$ bronchodilators. We present here the results of an efficacy study of a new preventive agent for asthma.

Nedocromil sodium has been available for the treatment for adult asthma since the late 1980s. The body of research that has built up since its introduction indicates that its effectiveness is based on an anti-inflammatory mode of action. $^{2-4}$ In addition to mast cell stabilising properties, ${ }^{56}$ nedocromil sodium can prevent the activation of and release of mediators from inflammatory cells. ${ }^{78}$ Comparative challenge studies have established its superiority over sodium cromoglycate. ${ }^{9-11}$

Published research on the use of nedocromil sodium in children is still relatively sparse, although clinical pharmacology work has shown that it is effective in the prevention of exercise induced bronchoconstriction ${ }^{12} 13$ and, more recently, in bronchoconstriction induced by fog $^{14}$ and cold air. ${ }^{15} \mathrm{~A}$ year long open assessment of nedocromil sodium has shown it to be a safe and well tolerated treatment. ${ }^{16}$ To date, controlled studies have examined its efficacy over four ${ }^{17}$ and eight ${ }^{18}{ }^{19}$ week periods of treatment. The trial described here has studied safety, efficacy, and tolerability over 12 weeks of treatment.

\section{Patients and methods}

Two hundred and seventy seven children, aged between 6 and 17 years with a reliable clinical diagnosis of asthma (a history of breathlessness and paroxysmal wheeze with or without nocturnal cough at least once per month for the last six months) were invited to participate in a double blind, group comparative trial. Parental written informed consent or witnessed verbal consent was obtained and the Italian Ministry of Health provided its approval. A two week baseline was followed by random allocation (using a preassigned code) to 12 weeks' treatment with $4 \mathrm{mg}$ nedocromil sodium (Tilade, Fisons) four times daily or a matching placebo preparation. The study treatment was taken in addition to the child's normal medication. No child had received nedocromil sodium before this study.

Throughout the trial the children (or their parents) kept a daily diary, scoring day and night time asthma and cough severity $(0=$ none to $4=$ very severe), use of all medication (including trial treatments), and the best of three measurements of morning and evening peak expiratory flow rate (PEF). The children visited the clinic on five occasions: on admission, at the end of the baseline, and at four week intervals during treatment. Pulmonary function (forced expiratory volume during the first second of expiration $\left(F E V_{1}\right)$, forced vital capacity $(F V C)$, and PEF $)$ and asthma severity $(0=$ no symptoms, $1=$ mild, 2 =moderate, $3=$ severe, $4=$ very severe) were measured on each occasion. Samples were taken at the first and final clinic visits for routine blood packed cell volume, red cell, white cell and platelet counts, haemoglobin, serum creatinine, and serum bilirubin concentrations and serum glutamic oxaloacetic transaminase and serum glutamic pyruvic transaminase activities and urine (protein, glucose, and blood) analyses. At visits during the treatment period the clinician discussed with the child/parent any unusual symptoms. At the 
final visit the clinician and the child/parent assessed the effectiveness of their test treatment ( 1 =very effective to $5=$ made condition worse).

A child was randomised to test treatment only if (1) he/she was able to use a pressurised aerosol and peak flow meter correctly, (2) blood and urinalysis were within the normal range for the laboratory, and (3) clinical symptoms were evident. This was defined as a total baseline symptom score of $\geqslant 20$ or a total baseline symptom score of $\geqslant 10$, plus at least 20 inhalations (or 10 nebulisations) of $\beta_{2}$ bronchodilator during the baseline.

\section{STATISTICAL ANALYSES}

Pulmonary function and laboratory data were analysed using Student's $t$ test. All other variables were analysed using the Mann-Whitney U test. Two tailed tests were used throughout at the $95 \%$ level of significance. The diary data were analysed using the means of the baseline and the four weeks between clinic visits. Data gathered at the end of baseline visit were used for the clinic baseline. All comparisons between treatments were made using changes from baseline.

Children withdrawn because of deteriorating asthma were included in an end point analysis using maximum asthma severity and opinion scores, and the mean of the last three days' diary data if they had used test treatment for at least seven days. All available data were included from patients withdrawn for other reasons.

\section{Results}

\section{PATIENT DEMOGRAPHICS}

Sixty eight of the 277 children studied did not proceed beyond the baseline: the majority did not satisfy the criteria for entry into the treatment period, others were uncooperative,

Table 1 Patient characteristics at baseline

\begin{tabular}{|c|c|c|}
\hline & $\begin{array}{l}\text { Nedocromil } \\
\text { sodium }\end{array}$ & Placebo \\
\hline $\begin{array}{l}\text { No of children: } \\
\text { Total } \\
\text { Boys } \\
\text { Girls }\end{array}$ & $\begin{array}{r}110 \\
78 \\
32\end{array}$ & $\begin{array}{l}99 \\
69 \\
30\end{array}$ \\
\hline $\begin{array}{l}\text { Mean age in years } \\
\text { Range }\end{array}$ & $\begin{array}{c}10 \cdot 0 \\
6-16\end{array}$ & $\begin{array}{l}9 \cdot 9 \\
6-17\end{array}$ \\
\hline $\begin{array}{l}\text { Type of asthma: } \\
\text { Extrinsic } \\
\text { Intrinsic } \\
\text { Mixed }\end{array}$ & $\begin{array}{r}42 \\
8 \\
60\end{array}$ & $\begin{array}{r}34 \\
6 \\
59\end{array}$ \\
\hline $\begin{array}{l}\text { Severity in past } 12 \text { months: } \\
\text { None } \\
\text { Mild } \\
\text { Moderate } \\
\text { Severe } \\
\text { Very severe } \\
\text { No record }\end{array}$ & $\begin{array}{r}1 \\
22 \\
59 \\
25 \\
2 \\
1\end{array}$ & $\begin{array}{r}0 \\
15 \\
57 \\
26 \\
1 \\
0\end{array}$ \\
\hline $\begin{array}{l}\text { Mean duration of asthma in years } \\
\text { Range }\end{array}$ & $\begin{array}{l}6 \cdot 0 \\
1-15\end{array}$ & $\begin{array}{l}5 \cdot 7 \\
1-12\end{array}$ \\
\hline Mean (SD) FEV (I) & $1 \cdot 73(0 \cdot 64)$ & $1.78(0.83)$ \\
\hline Mean (SD) \% reversibility FEV & $18 \cdot 5(20 \cdot 3)$ & $17 \cdot 9(17 \cdot 6)$ \\
\hline $\begin{array}{l}\text { Current medication: } \\
\text { Inhaled bronchodilators } \\
\text { Oral bronchodilators } \\
\text { Theophylline } \\
\text { Inhaled steroids } \\
\text { Oral steroids } \\
\text { Sodium cromoglycate } \\
\text { Ketotifen } \\
\text { Hyposensitisation } \\
\text { No record }\end{array}$ & $\begin{array}{r}\mathbf{6 0} \\
\mathbf{9} \\
\mathbf{6} \\
1 \\
1 \\
\mathbf{4} \\
2 \\
7 \\
22\end{array}$ & $\begin{array}{r}53 \\
5 \\
5 \\
7 \\
2 \\
3 \\
3 \\
10 \\
21\end{array}$ \\
\hline
\end{tabular}

had a concurrent illness, or their asthma deteriorated. The 110 children randomised to nedocromil sodium had a six year (range 1-15) history of asthma. Atopy (as judged by radioallergosorbent and skin prick tests) was evident in 102 children. At admission mean (SD) FEV was $1.73(0.64)$ litres $(18.5(20.3) \%$ reversible after a standard dose of inhaled bronchodilator). The 99 children randomised to placebo had a $5 \cdot 7$ year (range 1-12) history of asthma. Atopy was evident in 93 children, and $\mathrm{FEV}_{1}$ was 1.78 $(0.83)$ litres $(17 \cdot 9(17 \cdot 6) \%$ reversible). Over $50 \%$ of children from both treatment groups were maintained on inhaled bronchodilator treatment Full patient demographics are given in table 1 .

\section{PATIENT WITHDRAWALS AND COMPLIANCE}

Fifty four children were withdrawn from the study as a result of deteriorating asthma, noncooperation, concurrent illness, and suspected adverse reactions (table 2). Data from 19 children (nine on nedocromil sodium) withdrawn because of deteriorating asthma were included in an end point analysis.

With the exception of 11 children (all withdrawals) test treatment usage was excellent. There was no evidence of any test treatment related effects leading to poor compliance. Three children used treatments for approximately half the time during weeks 5-8 (two on nedocromil sodium) and weeks 9-12 (one on placebo). These data were excluded.

During the study additional medication was used by similar numbers of children as follows: short course inhaled corticosteroids (nedocromil sodium/placebo; 16/12), oral bronchodilators $(19 / 16)$, sodium cromoglycate $(3 / 2)$, and ketotifen (1/0). Fifteen (9/6) of these children were among those withdrawn-mainly because of deteriorating asthma.

\section{EFFICACY}

Statistically significant differences in favour of nedocromil sodium were seen for total symptom score during weeks $1-4,5-8(\mathrm{p}<0.05)$, and 9-12 $(\mathrm{p}<0.01)$. Total symptom severity was reduced by half in children treated with nedocromil sodium, compared with a $9 \%$ reduction in children treated with placebo (fig 1). Most of the improvement in the nedocromil sodium group occurred during the first four weeks. Improvements in individual symptoms favoured nedocromil sodium at all time points: between treatment differences were significant throughout for daytime asthma and during weeks $1-4$ and 5-8 for night time asthma.

Significant treatment differences $(p<0.05)$ in

Table 2 Patient withdrawals. Figures are number (\%)

\begin{tabular}{lcc}
\hline Reason for withdrawal & $\begin{array}{l}\text { Nedocromil } \\
\text { sodium }\end{array}$ & Placebo \\
\hline Deterioration of asthma & $10(9 \cdot 1)$ & $13(13 \cdot 1)$ \\
Non-cooperation & $17(15 \cdot 5)$ & $5(5 \cdot 1)$ \\
Concurrent illness & $5(4 \cdot 5)$ & $2(2 \cdot 0)$ \\
Adverse reaction & $1(0 \cdot 9)$ & $1(1 \cdot 0) \dagger$ \\
Total & $33(30 \cdot 0)$ & $21(21 \cdot 2)$ \\
\hline
\end{tabular}

'Nausea, headache, and sleepiness (28 days' treatment). tDyspnoea (seven days' treatment) 
favour of nedocromil sodium were seen at each clinic assessment of asthma severity $(p<0.01$; week 4). After 12 weeks, the asthma assessment in the nedocromil sodium group (percent with no symptoms/mild/moderate symptoms) was 38/38/10 compared with a pretreatment baseline of $1 / 39 / 43$. Corresponding figures for the placebo treated children were 27/29/25 (baseline: $2 / 36 / 54$ )

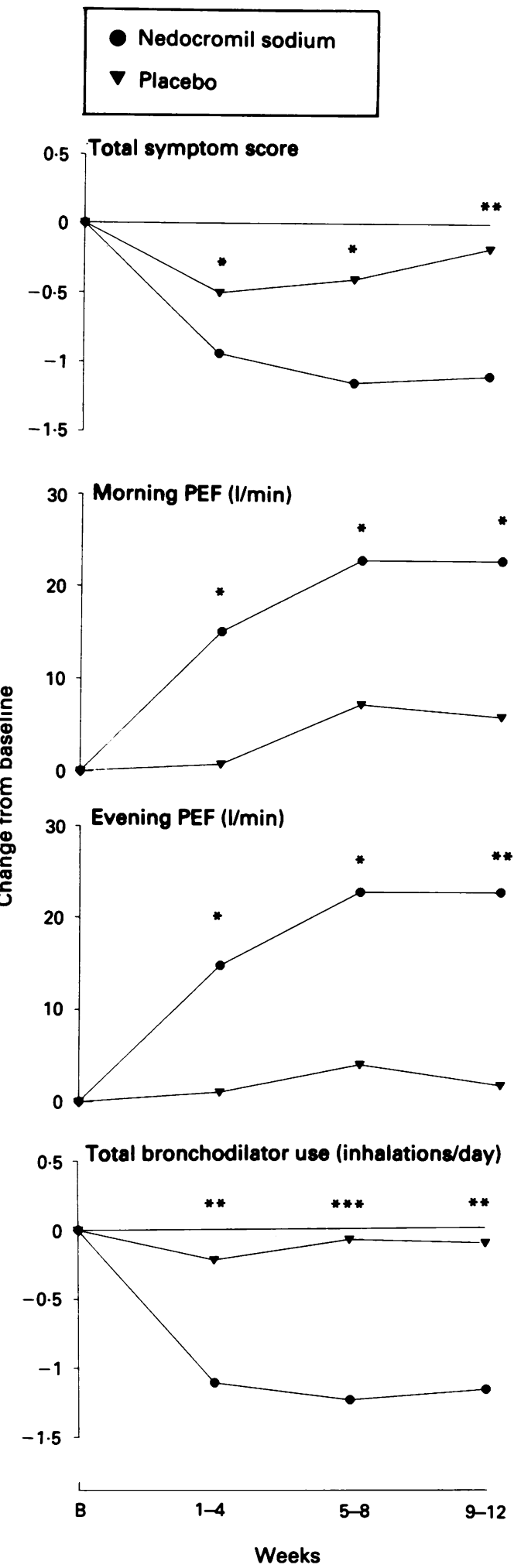

Figure I Diary card variables: mean change from baseline (B). Values at baseline were similar between treatment groups, as follows (nedocromil sodium/placebo): total symptom score: $2 \cdot 22 / 2 \cdot 05$; morning PEF: $281 \cdot 0 \mathrm{l} / \mathrm{min} / 287 \cdot 1$ l/min; evening PEF: $289 \cdot 1 \mathrm{l} / \mathrm{min} / 297 \cdot 4 \mathrm{l} / \mathrm{min}$; total bronchodilator use: $1 \cdot 91 / 1 \cdot 30$ inhalations/day, *: $p<0.001 ;{ }^{* *} p<0.01 ;{ }^{*} p<0.05$.
Mean peak flow rates increased from baseline values in the nedocromil sodium treated group by $23 \mathrm{l} / \mathrm{min}$ (fig 1 ). There was little change from baseline in the placebo treated group (maximum $7 \mathrm{l} / \mathrm{min}$ morning PEF, weeks 5-8). The between treatment differences were significantly $(p<0.05)$ in favour of nedocromil sodium throughout the study $(p<0.01$; evening peak flow during weeks 9-12).

Increases in $\mathrm{FEV}_{1}$ and FVC (maximum 9\% and $6 \%$, respectively) for both treatment groups were recorded at the clinic: between treatment differences were not significant. Peak flow increased $15 \%$ over baseline in the nedocromil sodium group, compared with $9 \%$ in the placebo group. The between treatment difference was significant $(p=0.02)$ at the week 4 visit.

Total inhaled bronchodilator use was reduced by more than half $(61 \% ; 1 \cdot 17$ actuations and/or nebules per day) in nedocromil sodium treated children (fig 1). There was a negligible reduction in use $(8 \%)$ among those children treated with placebo. The difference between treatments was significantly $(p<0.01)$ in favour of nedocromil sodium at all time points (weeks 5-8; $<<0.001$ ). As with total symptom score, the majority of the reduction occurred during the first four weeks. Subanalysis of day and night time use revealed significant between treatment differences in favour of nedocromil sodium during all time periods.

Sixty eight $(78 \%)$ of the children/parents reported that nedocromil sodium was a very or a moderately effective treatment (opinion scores 1 and 2) compared with $52(59 \%)$ of the recipients of placebo $(p<0.001)$. Clinicians opinions were similar $(p<0.01)$ : nedocromil
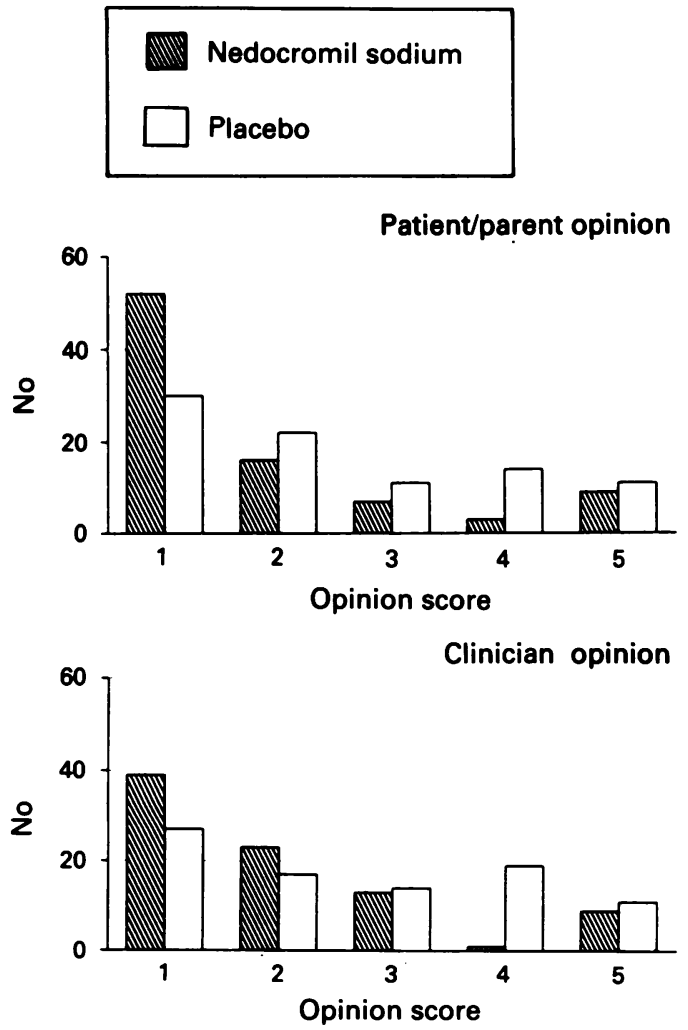

Figure 2 Number of patients who reported, or who were considered by the clinician, to have received a very effective (opinion score 1), moderately effective (2), slightly effective (3), or ineffective treatment (4); opinion score $5=$ made the condition worse. 
sodium was considered very or moderately effective in 62 children (73\%), placebo in 44 (50\%) children (fig 2).

\section{ACCEPTABILITY AND SAFETY}

No significant between treatment differences were found in the pretreatment laboratory variables or in the changes from pretreatment to post-treatment.

During the baseline seven children subsequently randomised to nedocromil sodium and three to placebo reported unusual symptoms (headache, cough, fever, pain, wheeze, and vomiting). During the treatment period, 24 nedocromil sodium and 30 placebo treated children reported at least one unusual symptom. Most frequently reported were pharyngeal tracheal symptoms (nedocromil sodium/placebo; $11 / 6)$, headache (4/1), cough (3/3), fever $(3 / 3)$, bronchospasm/wheeze/dyspnoea (0/4), and eczema symptoms $(2 / 2)$. One uncooperative child reported a 'bad taste' associated with placebo treatment.

\section{Discussion}

The results of our study present good evidence for the efficacy of nedocromil sodium in childhood asthma. Although near the lower limit, mean baseline PEF was within the normal range for these children. Mean $\mathrm{FEV}_{1}$ was approximately $80 \%$ of predicted normal for height and sex. Mean symptom scores and inhaled bronchodilator use were also low. Despite this, baseline monitoring indicated the potential for improvement, and during the treatment phase all diary card variables favoured nedocromil sodium. There were statistically significant treatment differences in favour of nedocromil sodium for total symptom score (and day and night time asthma scores), twice daily PEF measurements, and inhaled bronchodilator use. Clinician assessment of asthma severity and child/parent and clinician opinions of efficacy also significantly favoured nedocromil sodium. Clinic lung function, on the other hand, was not significantly improved.

Our findings of significant improvements in symptoms and bronchodilator use support the earlier research ${ }^{18} 19$ in the more severe patient but also suport the potential use of nedocromil sodium in milder forms of disease. ${ }^{17}$ Interestingly, a subanalysis of the effect of treatment on each child's worst baseline symptom showed significant improvements at each time point. Nedocromil sodium appeared to have a greater therapeutic effect in our study. Group size was much larger, however, thereby increasing the ability of the study to detect treatment differences.

In common with clinical experience with adults ${ }^{20}$ nedocromil sodium appears to be fairly rapid in onset of effect in children. Significant differences have been observed within two to three weeks. ${ }^{17-19}$ In the present study the majority of the improvements in signs and symptoms occurred during the first four week period.
Nedocromil sodium appears to be well tolerated by children. ${ }^{16-19}$ Monitoring of reports of unusual symptoms before the use of study treatments suggests to us that the use of nedocromil sodium may result in occasional reports of sore throat and headache. This is similar to findings from a smaller group of patients. ${ }^{17}$ In the year long study nausea was reported and one incidence of bronchospasm. ${ }^{16}$ Unpleasant taste, a recognised finding in a minority of adults, ${ }^{2}$ has specifically not appeared in the paediatric literature. ${ }^{17} 18$ This is in agreement with our own results.

Evidence, in vitro and clinical, for an antiinflammatory mechanism of action of nedocromil sodium is compelling. Both nedocromil sodium and corticosteroids inhibit the antigen induced late phase reaction, ${ }^{21} 22$ which is known to be refractory to inhaled bronchodilators ${ }^{22}$ and characterised by oedema and mucus hypersecretion. ${ }^{23}$ In adults nedocromil sodium has been shown to provide the therapeutic equivalent of approximately $400 \mu \mathrm{g}$ inhaled corticosteroid per day $^{24}$ and a paediatric study ${ }^{16}$ reported improvements in lung function and symptoms despite cessation of inhaled steroid and theophylline treatment in many of the children. Prevention of bronchoconstriction as a result of non-immunological challenge ${ }^{-11} 25$ indicates that nedocromil sodium probably affects sensory $\mathrm{C}$ fibres and local axon reflexes. These latter studies have so far only been carried out in adults but we have no reason to suppose that the mechanism of asthma differs between children and adults, although the influence of sequelae of long term disease (muscle hypertrophy and scarring) cannot be ignored.

A recent study has attempted to extend the observations of nedocromil sodium's inhibitory effect on cell activation in vitro to a controlled paediatric trial. ${ }^{26}$ Administration of nedocromil sodium for three months to asthmatic children led to a significant reduction in superoxide anion production by opsonised zymosan stimulated granulocytes. We are only aware of one similar study in adults in which nedocromil sodium, but not sodium cromoglycate, inhibited the abnormal in vitro response to aspirin of platelets from aspirin sensitive asthmatics. ${ }^{27}$ Further ex vivo studies are needed to clarify the cellular action of nedocromil sodium in asthma.

In terms of our own results we can conclude that nedocromil sodium was able to improve daily asthma symptoms and lung function, concurrent with a significant reduction in daily bronchodilator intake, in children with mild to moderately severe disease.

We wish to thank Fisons plc, Pharmaceutical Division, for the provision of the coded clinical trial supplies and the statistical analysis.

The individual data described in the results section are available from the authors on request.

1 Warner JO. Management of childhood asthma. Allergy Proc 1991;12:5-8.

2 Gonzalez JP, Brodgen RN. Nedocromil sodium. A preliminary review of its pharmacodynamic and pharmacokinetic properties, and therapeutic efficacy in the treatmen of reversible obstructive airways disease. Drugs 1987;34:

3 Rainey DK. Nedocromil sodium $\left(\right.$ Tilade $^{\mathrm{R}}$ ): a review of preclinical studies. Eur Respir 7 1989;2(suppl 6):561S-5S 
4 Busse WW, Orr TSC, Pauwels R. International symposium on nedocromil sodium. Drugs 1989;37(suppl 1):1-137.

5 Riley PA, Mather ME, Keogh RW, et al. Activity of nedocromil sodium in mast-cell-dependent reactions in the rat. Int Arch Allergy Appl Immunol 1987;82:108-10.

6 Wells E, Jackson CG, Harper ST, et al. Characterization of primate bronchoalveolar mast cells. II. Inhibition of histamine, LTC and PGD 2 release from primate bronchomine, $\mathrm{LTC}_{4}$ and $\mathrm{PGD}_{2}$ release from primate bronchoalveolar mast cells and a comparison
mast cells. $\mathcal{F}$ Immunol $1986 ; 137: 3941-5$.

7 Thorel T, Joseph M, Tsicopoulos A, et al. Inhibition by nedocromil sodium of IgE-mediated activation of human mononuclear phagocytes and platelets in allergy. Int Arch Allergy Appl Immunol 1988;85:232-7.

8 Moqbel R, Cromwell O, Walsh GM, et al. Effects of nedocromil sodium (Tilade) on the activation of human eosinophils and neutrophils and the release of histamine from mast cells. Allergy 1988;43:268-76.

9 Richards R, Phillips GD, Holgate ST. Nedocromil sodium is more potent than sodium cromoglycate against AMPinduced bronchoconstriction in atopic asthmatic subjects. induced bronchoconstriction in a

10 Del Bufalo C, Fasano L. Patalano F, et al. Inhibition of foginduced bronchoconstriction by nedocromil sodium and sodium cromoglycate in intrinsic asthma: a double-blind, placebo-controlled study. Respiration 1989;55:181-5.

11 Dixon CMS, Ind PW. Inhaled sodium metabisulphite induced bronchoconstriction: inhibition by nedocromil sodium and sodium cromoglycate. Br 7 Clin Pharmacol 1990;30:371-6.

12 Henriksen JM. Effect of nedocromil sodium on exerciseinduced bronchoconstriction in children. Allergy 1988;43: 449-53.

13 Boner AL, Vallone G, Bennati D. Nedocromil sodium in exercise-induced bronchoconstriction in children. Ann Allergy 1989;62:38-41.

14 Murray M, Kinnear G, Milner AD. Prevention of fog-induced bronchoconstriction in asthmatic children by nedocromil sodium nebuliser solution. Eur Respir f 1989;2(suppl 8): 739S.

15 Monkhoff $M$, Wonne $R$, Ahrens $P$, et al. The protective effect of nedocromil sodium on the cold air reactivity of children with bronchial asthma. Atemwegs und Lungenkrankheiten 1990;16:268-70.

16 Madrazo JL, Casas C. Treatment with nedocromil sodium in children with chronic, severe asthma. Preliminary study.
Revista Española Alergologia Inmunología Clínica 1991;6 (suppl 2).

17 Businco L, Cantani A, Di Fazio A, et al. A double-blind placebo-controlled study to assess the efficacy of nedocromil sodium in the management of childhood grass-pollen asthma. Clin Exp Allergy 1990;20:683-8.

18 Strinati R. Nedocromil sodium. Medico Bambino 1987;10: $794-6$.

19 Corrias A, Minelli R, Pelosi U, et al. Nedocromil in the therapy of chronic asthma in children (double-blind, placebo-controlled study). Pediatr Med Chir 1990;12: 157-60.

20 Cherniack RM, Wasserman SI, Ramsdell JW, et al. A double-blind multicenter comparative study of the efficacy and safety of nedocromil sodium in the management of asthma. Chest 1990;97:1299-306.

21 Crimi E, Brusasco V, Crimi P. Effect of nedocromil sodium on the late asthmatic reaction to bronchial antigen challenge. J Alleroy Clin Immunol 1989;83:985-90.

22 Cockcroft DW, Murdock KY. Comparative effects of inhaled salbutamol, sodium cromoglycate, and beclomethasone dipropionate on allergen-induced early asthmatic responses, late asthmatic responses, and increased bronchial responsiveness to histamine. $\mathcal{F}$ Allergy Clin Immunol 1987;79: siveness

$23 \mathrm{Kay} \mathrm{AB}$. Anti-inflammatory agents in the treatment of bronchial asthma. In: Kay AB, ed. Allergy and asthma. New trends and approaches to therapy. Oxford: Blackwell Scientific Publications, 1989;151-70.

24 Bergmann $\mathrm{K}-\mathrm{Ch}$, Bauer C-P, Overlack A. A placebocontrolled, blinded comparison of nedocromil sodium and beclomethasone dipropionate in bronchial asthma. Curr Med Res Opin 1989;11:533-42.

25 Crimi N, Palermo F, Oliveri R, et al. Effect of nedocromil on bronchospasm induced by inhalation of substance $P$ in bronchospasm induced by inhalation of substan

26 Colazzo D, Brunetti L, Cardinale F, et al. Effect of nedocromil sodium on the production of superoxide anion in granulocytes in asthmatic children. Rivista Italiana di Pediatria 1990;16:563-6.

27 Marquette $\mathrm{CH}$, Joseph $\mathbf{M}$, Tonnel $\mathrm{AB}$, et al. The abnormal in vitro response to aspirin of platelets from aspirin-sensitive asthmatics is inhibited after inhalation of nedocromil sodium but not of sodium cromoglycate. Br 7 Clin Pharmacol 1990; 29:525-31. 